\title{
Atuação profissional no atendimento às vítimas de violências do sexo masculino: complexidade invisibilizada e ambiguidades
}

\author{
Professional performance in assisting male victims of violence: invisible complexity and ambiguities \\ Desempeño profesional en la atención a víctimas masculinas de violencia: complejidad invisible y \\ ambigüedades
}

Recebido: 12/02/2021 | Revisado: 18/02/2021 | Aceito: 21/02/2021 | Publicado: 22/02/2021

\author{
Amanda Pinheiro Said \\ ORCID: https://orcid.org/0000-0002-1786-9306 \\ Universidade de Brasília, Brasil \\ E-mail: amandapsaid@gmail.com \\ Liana Fortunato Costa \\ ORCID: https://orcid.org/0000-0002-7473-1362 \\ Universidade de Brasília, Brasil \\ E-mail: lianaf@terra.com.br
}

\begin{abstract}
Resumo
$\mathrm{O}$ atual cenário brasileiro de pesquisas que priorizam as violências contra meninos é escasso, especialmente aquelas que estudam as polivitimizações, ou seja, a ocorrência de mais de um tipo de violência para uma mesma vítima. O cenário de polivitimização é complexo e traz como consequência para a polivítima um acúmulo dos sintomas, por isso é fundamental que seus direitos sejam garantidos por meio de um atendimento intersetorial e interdisciplinar que dê conta da amplitude do fenômeno. Este texto faz parte de uma ampla pesquisa-ação, com viés qualitativo e ainda em andamento, e tem como objetivo apresentar as percepções de profissionais pertencentes e atuantes na rede pública de atendimento às vítimas do sexo masculino em um dos estados da federação do Brasil, a respeito da (poli)vitimização de meninos e de suas próprias práticas profissionais. Foram entrevistados 21 profissionais de sete diferentes setores que fazem parte do sistema de garantia de direitos: assistência social, educação, justiça, ministério público, saúde, segurança pública e sociedade civil. Após análise temática reflexiva, discute-se dois temas, construídos a partir das reflexões e opiniões das e dos participantes: "Polivitimização: raízes profundas, porém não visíveis" e "A atuação profissional com a (poli)vitimização de meninos". Em pesquisas futuras, sugere-se a condução de pesquisas semelhantes em outros estados da federação, para que seja ampliado o conhecimento a respeito da polivitimização e seja possível capacitar as e os profissionais que trabalham com o tema.
\end{abstract}

Palavras-chave: Profissionais; Abuso de criança; Vitimização; Intervenção psicossocial.

\begin{abstract}
The current Brazilian scenario of research that prioritizes violence against boys is scarce, especially those that study polyvictimizations, in other words, the occurrence of more than one type of violence for the same victim. The polyvictimization scenario is complex and brings as a consequence for the polyvictim an accumulation of symptoms, reason why it is essential that their rights are guaranteed through intersectoral and interdisciplinary care that accounts for the extent of the phenomenon. This text is part of a broad action-research, with qualitative bias and still in progress, and aims to present the perceptions of professionals who belong and work in the public service in one of the states of Brazil about the (poly) victimization of boys and their own professional practices. Twenty-one professionals from seven different sectors that guarantee the rights of children were interviewed. The sectors are: social assistance, education, justice, public ministry, health, public security and civil society. After reflexive thematic analysis, two themes are discussed, structured from the reflections and opinions from the participants: "Polyvictimization: deep roots, but not visible" and "Professional performance with the (poly) victimization of boys". In future research, it is suggested to conduct similar research in other states of Brazil, so that knowledge about polyvictimization is expanded and it is possible to enable professionals working with the theme.
\end{abstract}

Keywords: Professionals; Child abuse; Victimization; Psychosocial intervention.

\section{Resumen}

La actual etapa brasileña de investigación que prioriza la violencia contra la niñez es escasa, especialmente aquellos que estudian las polivitimizaciones, es decir, la ocurrencia de más de un tipo de violencia por una víctima. El escenario de polivictimización completa es resultado de una acumulación de síntomas para la polivictim, por lo que es fundamental que sus derechos estén garantizados a través de una atención intersectorial e interdisciplinaria que dé la 
magnitud del fenómeno. Este texto es parte de una amplia pesquisa-acción, con enfoque cualitativa y un proceso, y tiene como objetivo presentar las percepciones de los profesionales pertenecientes en el servicio público en uno de los estados de la federación brasileña, sobre (poli ) victimización de los niños y sus propias prácticas profesionales. Se entrevistaron 21 profesionales diferentes en diferentes sectores que formaban parte del sistema de garantía de derechos: asistencia social, educación, justicia, ministerio público, salud, seguridad pública y sociedad civil. Transcurrido un análisis temático reflexivo, el resultado y discusión de los temas, construido a partir de las reflexiones y opiniones de los participantes: "Polivitimización: raíces profundas, pero no visibles" y "Desempeño profesional con (poli) victimización infantil". En futuras investigaciones se sugiere realizar investigaciones similares en otros estados de la federación, de manera que se amplíe el conocimiento sobre la polivitimización y la posible capacitación de los profesionales que trabajan con la temática.

Palabras clave: Profesionales; Abuso de niños; Victimización; Intervención psicosocial.

\section{Introdução}

A violência contra crianças e adolescentes pode assumir diferentes formas e causar diferentes prejuízos e sintomas (Gauthier-Duchesne et al., 2017), não apenas às vítimas, mas também aos seus familiares. Dentre as várias pesquisas e produções de conhecimento existentes na área, as vítimas do sexo masculino ainda estão em desvantagem, se comparadas ao número de publicação referente às vítimas do sexo feminino. É comum que sejam conduzidas pesquisas abordando a violência contra crianças e adolescentes sem distinção entre meninos e meninas (Oliveira et al., 2014; Turner et al., 2016) ainda que já existam estudos que apontem diferenças significativas entre as vítimas do sexo masculino e feminino (Burnes et al., 2016; Hohendorff et al., 2017; Penso et al., 2019).

As vítimas de violência sexual do sexo masculino, por exemplo, tendem a demorar mais tempo mais tempo para revelar a violência sofrida e pedir ajuda (Hlavka,2016), aspecto que pode se repetir entre seus próprios familiares que também têm dificuldade de acionar os serviços e pedir auxílio. Alguns sintomas e prejuízos apresentados pelas vítimas de violência sexual também parecem ter como característica serem mais "externalizantes", como comportamentos de agressividade, inquietação e raiva (Guerra et al., 2016). Outro aspecto que também parece diferir entre meninos e meninas ocorre na própria dinâmica das violências, como nos processos de revitimização, ou seja, a ocorrência de mais de um episódio de um mesmo tipo de violência, e de polivitimização.

O conceito de polivitimização, cunhado pela primeira vez por Finkelhor et al. (2005), descreve o fenômeno em que uma mesma vítima sofre mais de um tipo de violência e, com isso, também acumula as consequências e os agravos decorrentes. É um tema extremamente relevante, porém pouco estudado no Brasil, ainda que estudos também pareçam apontar para a maior ocorrência dentre as vítimas do sexo masculino (Oliveira et al., 2014).

No Brasil, a ocorrência de violências contra crianças e adolescentes do sexo masculino, sendo apenas um episódio ou tipo único de vitimização, ou ainda um cenário de polivitimizações, coloca as vítimas e seus familiares dentro de um fluxo de instituições de atendimento que têm como objetivo interromper a(s) violência(s), proteger as vítimas e familiares e responsabilizar as/os possíveis autoras/es. Esse fluxo inclui a participação de diferentes profissionais com diversas formações e diferentes serviços e instituições e é previsto em vários dispositivos legais, como o Estatuto da Criança e do Adolescente (Brasil, 1990) e a Lei 13.431/2017 (Brasil, 2017) que normatiza e organiza o sistema de garantia de direitos (SGD) da criança e adolescente vítima ou testemunha de violência.

Nesse sistema, está proposta a implementação e articulação das políticas de atendimento de setores como a assistência social, a educação, a justiça, a saúde e a segurança pública (Brasil, 2017), numa tentativa de abarcar a complexidade que as situações de violências contra crianças e adolescentes requerem. Cada um desses setores têm atribuições distintas, embora complementares, e contam com várias instituições que executam as ações práticas da política pública de restabelecimento da proteção.

O setor da Assistência Social se volta para a preocupação com os direitos de cidadania garantindo o atendimento 
às necessidades básicas de populações vulnerabilizadas. Para execução das ações possui, dentre outras instituições, os Centros de Referência Especializado em Assistência Social (CREAS), que são unidades que oferecem atendimento às pessoas e famílias que vivem em situações de violência e de violação de direitos (Brasil, 2005). O setor da Educação visa avaliar e garantir a efetividade de programas que executam as políticas públicas para a educação, sendo seu âmbito de atuação, principalmente, a escola, por meio da participação de professores.

O setor Justiça compreende o segmento jurídico, com instituições pertencentes ao sistema judiciário - federal, de cada estado ou Distrito Federal - e ainda do Ministério Público, e visa o acesso da população à justiça, considerando a parceria entre e o Estado e a sociedade civil, buscando a promoção e integração do cidadão, e a diminuição das desigualdades sociais (Brito \& Bonini, 2019). Para a efetivação da política de proteção à infância, encontram-se as instituições normatizantes como Conselhos de Direitos, e operacionais como os Conselhos Tutelares, as delegacias de proteção à infância e adolescência (DPCA), e as promotorias de defesa da infância e adolescência.

O setor Saúde é o responsável pela adoção das medidas de atenção à saúde de crianças e adolescentes que cobre todo o período entre o pré natal e o final da infância, acompanhando o crescimento e desenvolvimento até a adolescência. Há uma compreensão deste crescimento em uma perspectiva integral (Ministério da Saúde, 2010), envolvendo a família e a sociedade, com uma determinação prática calcada em "Linhas de Cuidado". Além disso, prevê que os cuidados sejam ofertados em condição intersetorial, a partir de uma preocupação específica com a violência e violência sexual.

O setor de Segurança Pública atua por intermédio das secretarias estaduais e municipais de segurança pública que têm como uma de suas funções propor e executar ações que visem a redução da violência e da criminalidade. A operacionalização da proteção ocorre por meio de: delegacias, disque-denúncia, ouvidorias, polícias. Todas estas atribuições, distribuídas e interconectadas, constituem-se em dever frente à proteção da infância e juventude, e encontram respaldo na Constituição do Brasil de 1988 e no Estatuto da Criança e do Adolescente (ECA) (Brasil, 1990), que são os dois maiores orientadores legais nesta tarefa de cumprimento do SGD.

Justifica-se este texto pelo cenário de grande relevância social e acadêmica do conhecimento sobre as vítimas de violência sexual do sexo masculino, e a carência de estudos com foco em profissionais e instituições que atendem essas vítimas. Assim, o presente texto tem como objetivo apresentar as percepções de profissionais pertencentes e atuantes na rede pública de atendimento às vítimas do sexo masculino em um dos estados da federação do Brasil, a respeito da (poli)vitimização de meninos e de suas próprias práticas profissionais. Acredita-se que dar luz às percepções destes profissionais pertencentes ao SGD, apresentando as idiossincrasias, potencialidades e impasses, é um dos caminhos para o fortalecimento do bem-estar psicológico de crianças e adolescentes vítimas de violências, além de ser uma possibilidade de aumentar a eficácia da execução da política pública de proteção. Ao longo do texto, utiliza-se o termo polivitimização para indicar o fenômeno nomeado e reconhecido, e o termo (poli)vitimização para a ocorrência de violência múltipla, mas ainda não nomeada ou reconhecida como polivitimização.

\section{Metodologia}

Este trabalho faz parte de uma pesquisa com maior amplitude, ainda em andamento e, por ter um viés qualitativo, não considera a existência a priori de hipóteses sobre as construções de resultados que serão apresentados a seguir. Trata-se de uma pesquisa-ação (Barbier, 2004) e que, portanto, privilegia a participação e o envolvimento das e dos atores envolvidos com a questão de pesquisa (Pereira et al., 2018). Considera-se esse envolvimento importante como forma de aproximar o campo acadêmico e de pesquisa com o campo prático das e dos profissionais envolvidos, neste caso, com o atendimento às vítimas do sexo masculino. Essas características, valorizadas nos métodos de pesquisa-ação 
(Barbier, 2004; Pereira et al., 2018) estão presentes nesta pesquisa, qualitativa, que foi realizada em um dos estados da federação do Brasil. Os participantes foram divididos em três diferentes grupos: (1) meninos polivítimas, (2) familiares de meninos vítimas de violência sexual, e (3) profissionais da rede pública de atendimento e, para este manuscrito, foram consideradas apenas as considerações e reflexões das e dos participantes do Grupo 3, privilegiando-se a perspectiva das e dos profissionais da rede pública de atendimento aos meninos (poli)vítimas.

\subsection{Participantes}

São 21 profissionais da rede pública de atendimento de um dos estados da federação do Brasil, dentre eles 16 mulheres e 5 homens. A faixa etária com maior número de participantes foi de 37 a 44 anos (8 participantes), seguida da faixa etária entre 45 a 50 anos (6 participantes). Quase metade das e dos profissionais se declarou branco (n=11) e negro (pretos, $n=2$ e pardos, $n=8$ ) e $81 \%$ se declararam casados ou em união consensual. Em relação ao grau de escolaridade, $62 \%$ das e dos participantes possuíam ensino superior completo, 19\% estavam com mestrado em andamento, 9,5\% tinham mestrado completo e essa mesma porcentagem $(9,5 \%)$ tinham doutorado completo.

As e os participantes pertenciam a instituições e serviços dos cinco setores integrantes do sistema de garantia de direitos (SGD), citados anteriormente - assistência social, educação, justiça, saúde e segurança pública - e ainda dos setores Ministério Público e Sociedade Civil. Nesta pesquisa, as e os participantes do Ministério Público (MP) foram subdivididos e considerados à parte do setor Justiça, levando em consideração que o MP atua de forma independente da justiça, ainda que sejam atribuições interrelacionadas. A Sociedade Civil também foi considerada como um sétimo setor, uma vez que sua participação no SGD é fundamental e difere dos outros setores, tendo como principal atribuição fazer o controle das ações e políticas públicas, cobrando a execução, efetivação e qualidade das mesmas (Centro de Referência em Educação Integral, 2014). Assim, as e os 21 participantes deste trabalho foram caracterizados: Assistência Social $(n=1)$, Educação $(n=1)$, Justiça $(n=6)$, Ministério Público $(n=3)$, Saúde (n=3), Segurança Pública (n=6) e Sociedade Civil $(\mathrm{n}=1)$. Neste manuscrito, de forma a garantir o sigilo da identidade das e dos participantes, eles serão referidos com as iniciais da sua área de atuação, acrescido de um número ordinal: ASoc1; Edu1; Jus1/Jus2.; MPub1/MPub2.; Sau1/Sau2; SPub1/SPub2; SCiv1.

\subsection{Instrumentos}

Foram utilizados três instrumentos: um roteiro com oito perguntas abertas e seis frases para serem completadas e um questionário sociodemográfico, com 14 itens. As questões do roteiro tiveram como objetivo abordar a trajetória profissional das e dos participantes e também conhecer suas ideias e percepções sobre violências e polivitimização contra crianças e adolescentes, especialmente as do sexo masculino. As frases para serem completadas abordavam a percepção das e dos profissionais sobre violência e seus impactos para meninos, meninas e familiares. Já o questionário possuía itens a respeito de aspectos individuais de cada participante, como estado civil e idade, e também aspectos profissionais e acadêmicos, como o grau de escolaridade, área de formação e tempo de atuação naquela instituição.

A compreensão de instrumentos em pesquisas qualitativas, como a deste trabalho, é de que os instrumentos são meios para facilitar a expressão das e dos participantes e, por isso, o instrumento aqui utilizado não foi acessado de forma rígida, mas sim de forma a facilitar e contribuir para a expressão das e dos participantes e desta forma possibilitar a construção de conhecimento (González-Rey, 2010), neste caso, a percepção dos profissionais da rede pública de atendimento às vítimas de violências do sexo masculino. 


\subsection{Procedimentos de coleta}

O primeiro procedimento foi a confecção de uma lista inicial com nomes de possíveis participantes que, a priori, deveriam representar cada um dos grandes setores mencionados, para abarcar o percurso geral que o menino vítima de violência(s) faz na rede pública de atendimento. Essa lista foi confeccionada a partir da rede profissional e de contato da pesquisadora principal que, por sua vez, também atuava como profissional de uma instituição do SGD. À medida que foram sendo realizadas as entrevistas, foi sendo percebida a necessidade de ampliação dessa lista de forma a incluir profissionais de outras instituições que, embora fossem pertencentes aos mesmos setores, possuíam funções e atribuições bastante distintas, pois trabalhavam em instituições diferentes. A ampliação da lista para inclusão de outros participantes foi ocorrendo a partir da indicação das e dos próprios profissionais que estavam sendo entrevistados.

Previamente ao recrutamento, foram definidos quatro critérios para inclusão das e dos profissionais nesta pesquisa: (1) ter experiência profissional com a temática da violência contra crianças e adolescentes há pelo menos um ano, (2) ser maior de 18 anos, (3) trabalhar em instituição e/ou serviço que fizesse parte da rede pública de atendimento de crianças e adolescentes no Distrito Federal, Brasil, e (4) ter consentido a participação na pesquisa, após as autorizações das chefias, nos casos em que isso fosse necessário.

O convite para participação na pesquisa foi feito por mensagens de texto enviadas aos profissionais ou ainda emails enviados diretamente aos profissionais ou às instituições. Esse procedimento ocorreu 29 vezes, entre março e julho de 2020, e nesses convites era feita a apresentação da pesquisadora principal e do projeto de pesquisa. Foram recebidas 20 respostas afirmativas, que se desdobraram nas 20 entrevistas realizadas, uma resposta negativa e sete contatos não foram respondidos. Além desses, houve uma entrevista que foi agendada, mas precisou ser desmarcada por um problema pessoal da profissional que seria entrevistada.

Em função da pandemia do novo coronavírus (OPAS, 2020) foi oferecida a possibilidade das entrevistas ocorrerem de forma online, mas seis delas ainda foram conduzidas presencialmente, atendendo as preferências das e dos próprios profissionais entrevistados e seguindo todos os protocolos de saúde e segurança. As outras 14 entrevistas foram conduzidas de forma online, por videochamada. Uma das 20 entrevistas teve a participação de duas profissionais da mesma instituição, também a pedido das próprias profissionais. As entrevistas tiveram em média uma hora de duração, sendo 35 minutos a entrevista mais breve e 1 hora e 34 minutos a mais longa. Todas foram gravadas em áudio para posterior transcrição e análise.

O roteiro com questões abertas foi utilizado nos momentos das entrevistas com as e os participantes. Já o questionário sociodemográfico foi enviado exclusivamente de forma online aos participantes para preenchimento por eles, após o momento da entrevista. No início de todas as entrevistas foi também lido e assinado o Termo de Consentimento Livre e Esclarecido com as e os participantes. Foram seguidos todos os cuidados éticos para preservar o sigilo das e dos participantes, desde o momento do convite e apresentação da pesquisa até à exposição do conteúdo de suas falas, como feito neste trabalho. Esta pesquisa foi aprovada pelo Comitê de Ética e Pesquisa do Instituo de Ciências Humanas e Sociais da Universidade de Brasília Parecer Número 3.925.299.

\subsection{Procedimentos de análise}

Neste trabalho os procedimentos de análise foram guiados pela ferramenta da análise temática reflexiva de Braun e Clarke (2006; 2019), que permite identificar, analisar e descrever padrões (themes) dos dados coletados a partir de uma compreensão de que pesquisas qualitativas, como esta em questão, são instâncias criativas, reflexivas e subjetivas. Foi considerado e valorizado, portanto, a subjetividade de todos os envolvidos - equipe de pesquisa e participantes - como defendem as autoras (Braun \& Clarke, 2019), as pesquisas qualitativas trazem em si um sentido de construção e criação, 
de forma contextual e processual desde os momentos de coleta de dados, sem que se perca o rigor e a estrutura necessária para pesquisas científicas de qualidade.

A proposta de análise temática reflexiva compreende a construção dos temas a partir dos conteúdos semânticos e explícitos nas falas das e dos participantes, mas também nos conteúdos latentes, necessitando de um processo interpretativo intenso e que vai além da mera descrição das informações coletadas. Para isso, são sugeridas seis fases para a análise dos dados (Braun \& Clarke, 2006; Braun et al., 2019), que foram seguidas neste trabalho: (1) familiarização, (2) geração de códigos iniciais, (3) construção inicial de temas, (4) revisão e definição de temas, (5) definição e nomeação e (6) produção do relato.

A primeira etapa da análise deste trabalho começou ainda no momento em que a própria pesquisadora realizou as transcrições das 20 entrevistas, contabilizando pouco mais de 20 horas de material. O momento seguinte, de leitura de todo o material, deu continuidade à etapa de familiarização, por meio de notas que a pesquisadora tomou de forma livre, curiosa e atenta.

Na segunda etapa, foram selecionados 688 trechos significativos das transcrições e eles foram agrupados em 83 códigos. Esse processo de codificação não foi uma busca de evidências para temas já pré-concebidos, seja pela pesquisadora ou pela literatura, mas um processo de identificação de sentidos nos trechos selecionados. Nesta etapa, no mesmo trecho pôde ser agrupado de um a quatro códigos distintos.

$\mathrm{Na}$ etapa seguinte, de construção de temas em potencial, códigos semelhantes foram agrupados ou ainda foram eles mesmos transformados em temas. Importa diferenciar os conceitos de temas e códigos, enquanto distintas unidades de análise, já que os temas são unidades mais complexas, que capturam múltiplas observações ou facetas do material interpretado e já os códigos são unidades de análise mais simples e objetivas. Ao fim desta terceira etapa, foram construídos 21 temas em potencial.

Na quarta etapa, foi feita a revisão e definição dos temas, relendo os trechos selecionados e voltando ao material bruto das transcrições, num processo recursivo previsto, que valoriza a necessidade de uma reflexão e engajamento profundos da equipe de pesquisa com as informações. Como resultado, foram definidos 15 temas com 597 trechos distribuídos entre eles.

Na quinta etapa, foi feita a nomeação final dos temas e construídos 34 subtemas àqueles temas particularmente amplos. Também nesta etapa, foram feitas pequenas definições deles, de forma a facilitar a organização e delimitação de fronteiras entre os temas e subtemas. Por fim, a sexta e última etapa foi o momento de construção do relato a partir dos resultados construídos da pesquisa, fase que também consistiu na revisão final do conteúdo, de sua estrutura e nomes.

\section{Resultados e Discussão}

Para exposição e discussão neste manuscrito foi feito um recorte e selecionados dois dos 15 temas construídos na mencionada pesquisa mais ampla sobre polivitimização de meninos. Desta forma, espera-se responder ao objetivo do manuscrito e apresentar a percepção das e dos profissionais sobre polivitimização e sobre as suas práticas profissionais. $\mathrm{O}$ Quadro 1 apresenta os dois temas que serão explorados, com suas respectivas definições e subtemas. 
Quadro 1. Temas, subtemas e suas respectivas definições.

\begin{tabular}{|c|c|c|c|}
\hline Tema & Definição & Subtema & Definição \\
\hline \multirow{3}{*}{$\begin{array}{l}\text { Polivitimização: } \\
\text { raízes profundas, mas } \\
\text { não visíveis }\end{array}$} & \multirow{3}{*}{$\begin{array}{l}\text { A existência do fenômeno } \\
\text { polivitimização e toda sua } \\
\text { complexidade são reconhecidas pelos } \\
\text { profissionais, mas há muitos de seus } \\
\text { aspectos - a começar pelo nome - que } \\
\text { seguem invisibilizados. }\end{array}$} & $\begin{array}{l}\text { A polivitimização } \\
\text { existe, mas não é } \\
\text { assim nomeada }\end{array}$ & $\begin{array}{l}\text { Profissionais percebem a alta } \\
\text { frequência de ocorrência de } \\
\text { polivitimização em seus } \\
\text { trabalhos, mas não conhecem ou } \\
\text { usam este termo. }\end{array}$ \\
\hline & & \begin{tabular}{|c|} 
Ambiguidade na \\
atuação profissional \\
sobre polivitimização
\end{tabular} & $\begin{array}{l}\text { Há o reconhecimento de que a } \\
\text { polivitimização difere das } \\
\text { vitimizações únicas, mas não há } \\
\text { um protocolo diferenciado para } \\
\text { atendimento, ação ou intervenção }\end{array}$ \\
\hline & & $\mid \begin{array}{c}\text { A vitimização sexual } \\
\text { às vezes faz sombra } \\
\text { às outras violências }\end{array}$ & $\begin{array}{l}\text { A violência sexual nem sempre é } \\
\text { a única violência, ou a mais } \\
\text { impactante, mas costuma ser a } \\
\text { que mais chama atenção das } \\
\text { famílias e dos profissionais }\end{array}$ \\
\hline \multirow{2}{*}{$\begin{array}{l}\text { A atuação profissional } \\
\text { com a } \\
\text { (poli)vitimização de } \\
\text { meninos }\end{array}$} & \multirow{2}{*}{$\begin{array}{l}\text { A atuação profissional com meninos } \\
\text { vítimas ou polivítimas é diversa e } \\
\text { caracterizada tanto por suas } \\
\text { experiências prévias como por } \\
\text { ambiguidades e confusões na prática } \\
\text { profissional }\end{array}$} & $\begin{array}{l}\text { As vantagens da } \\
\text { experiência }\end{array}$ & $\begin{array}{l}\text { Quanto mais experiência com o } \\
\text { tema, mais sensível e qualificado } \\
\text { o profissional tende a estar }\end{array}$ \\
\hline & & $\begin{array}{c}\text { Ambiguidades e } \\
\text { confusões na atuação } \\
\text { profissional }\end{array}$ & $\begin{array}{l}\text { Profissionais estão em construção } \\
\text { sobre o tema da vitimização } \\
\text { sexual de meninos e ainda se } \\
\text { posicionam de forma confusa e } \\
\text { estereotipada }\end{array}$ \\
\hline
\end{tabular}

Fonte: Resultados construídos a partir das transcrições das entrevistas realizadas com as e os participantes da pesquisa-ação que originou este texto.

Observa-se, neste quadro, como cada um desses temas é amplo em sentidos e significados e que seus respectivos subtemas são aspectos presentes e que se relacionam aos temas, mas que, por sua vez, apresentam em maior detalhe um ou outro determinado aspecto. Para esses dois temas, o número de trechos que foi inicialmente selecionado foi de 55, com falas advindas de todos os setores, menos da participante da "Sociedade Civil". Destes 55 trechos, foram escolhidos dez para ilustrar. Tais trechos estão apresentados a seguir, na discussão de cada tema e subtema.

\subsection{Tema 1: "Polivitimização: raízes profundas, mas não visíveis"}

\subsubsection{Subtema 1.1: A polivitimização existe, mas não é assim nomeada}

Um primeiro aspecto fundamental no estudo sobre polivitimização é justamente a sua (não) nomeação. Como pode ser observado no trecho de uma agente da Polícia Civil (apenas um dos exemplos de outras falas com o mesmo conteúdo), a polivitimização é um fenômeno que parece ser mais a regra do que a exceção nos serviços de atendimento 
público, mas a não nomeação do fenômeno como tal pode ser vista como o primeiro elo frágil do complexo circuito que a polivitimização faz parte.

"Para ser bem sincera, antes de você vir com esse contexto de polivitimização, eu nunca tinha. nunca tinha pensado nisso. a gente sabe assim.. na verdade é raro a violência, tecnicamente, ela vir isolada (...) então você sempre tem assim a lesão corporal junto com uma ameaça, a violência sexual também junto com uma ameaça, ou a violência sexual junto com uma alienação parental... então eu nunca tinha me atentado pra esse conceito ...” (SPub1)

Tal fragilidade gira em torno dos impactos da não nomeação de um fenômeno, uma vez que os processos de nomeação, consideração, percepção e identificação caminham juntos e retroalimentam-se. Pelo relato é possível observar a existência de um conhecimento prático, advindo da experiência e do trabalho na área, que auxilia a compreensão de que a ocorrência de uma única violência é fenômeno incomum. A dificuldade de nomeação da polivitimização ocorre ainda que estudos sobre o fenômeno já estejam publicados há mais de 15 anos (Finkelhor et al., 2005; Finkelhor et al., 2007).

A fala a seguir, de uma profissional que trabalha na atenção básica de saúde, mostra como são muitos os diferentes tipos de violência que estão presentes no seu dia-a-dia de trabalho e como as vítimas do sexo masculino também estão expostas, ainda que cheguem de forma menos específica nessas unidades básicas de saúde:

"Então aqui a gente sabe o quanto que a comunidade vive a violência no dia a dia, o quanto que a população passa por situações mais diversas, assim, de violência. É violência do Estado, é violência urbana, é violência da ausência do Estado, são... organizações criminosas, que a gente pode identificar como criminosa, é violência de gênero ou violência contra crianças e adolescentes, enfim.. Inúmeras... abusos mais diversos. e aí os meninos são alvos, claro, também.. só que não chega aqui como demanda específica direito, assim, é difícil a gente encontrar isso de forma mais.. desenhada,, bem delineada, assim." (Sau1)

Em 2011, Finkelhor et al. atualizaram o questionaram utilizado para pesquisar a polivitimização, o Juvenile Victimization Questionnaire - JVQ 2nd version - e adicionaram cinco outros grupos de violências - (1) exposição à violência familiar ou de pares, (2) violência ou ameaça na escola, (3) outras agressões severas, (4) vitimização eletrônica, (5) exposição à violência comunitária -, além dos cinco grupos principais de violências: (1) crimes convencionais, (2) maus tratos, (3) vitimização por pares, (4) vitimização sexual e (5) testemunhar violência ou violência indireta. O JVQ é um importante instrumento nos estudos sobre polivitimização, elaborado pelos autores que também começaram a estudar este tema e que é utilizado em diversos estudos (Guerra, Pereda et. al, 2016). Ainda que abrangente e detalhado, há tipos de violências, como a ausência ou negligência do Estado citadas no trecho da fala da participante Sau.1, que não estão descritas no JVQ - 2nd version (Finkelhor et al., 2011).

Tal cenário de violência comunitária e urbana, que inclui a ausência do Estado no estabelecimento e/ou cumprimento de políticas públicas, representa na sociedade brasileira atual um desafio à parte, uma vez que as raízes dessas violências urbanas e estruturais são tão profundas e enraizadas que, às vezes, nem são visíveis e percebidas (Soares, 2015). Essa invisibilidade, porém, não significa a não percepção da ocorrência do fenômeno, neste caso a polivitimização. Ou seja, há a compreensão da existência de episódios de violência urbana e da negligência do Estado, como citado pela profissional Sau1, mas sua ocorrência de forma frequente e cotidiana muitas vezes gera uma naturalização por parte das próprias vítimas, da sociedade de que fazem parte, e também das e dos profissionais (Araújo 
\& Ataíde, 2018). É possível, portanto, que as vítimas de violência sexual do sexo masculino que chegam aos serviços de saúde tenham, em sua trajetória de vida, outras violências como "estar exposto à tiroteiros" ou mesmo "presenciar agressões à terceiros com uso de armas" (Finkelhor et al., 2011), porém a alta frequência de ocorrência de tais episódios terminam por se caracterizarem, como a profissional de saúde mencionou, demandas não definidas ou não delineadas.

\subsubsection{Subtema 1.2: Ambiguidade na atuação profissional sobre polivitimização}

Além da não nomeação do fenômeno polivitimização dificultar sua compreensão e identificação, também pode acarretar como consequência ambiguidades ou mesmo prejuízos na atuação profissional. As ambiguidades estão presentes porque ao mesmo tempo em que se reconhece a necessidade de ações e intervenções diferenciadas diante do relato de mais de uma violência, não existe um protocolo ou procedimento diferenciado para esses casos de polivitimização de meninos, como é possível observar na fala de um profissional de serviço ambulatorial de saúde especializado em violência:

“Sim! Com certeza! Muda.. Muda o tipo de intervenção.. muda porque... (pausa)... muda porque.. ah... muda bastante! Porque... eu posso fazer uma intervenção aqui no grupo, trabalhando a questão do abuso da criança, proteção do corpo... mas... como trabalhar somente isso, se ela tá suscetivel a outros tipos de violência?" (Sau2)

Nesta fala, embora a primeira resposta e reação do profissional seja de logo reconhecer uma intervenção diferente nos casos de ocorrência de mais de um tipo de violência, ou seja, em casos de polivitimização, há alguma hesitação em sua fala no sentido de explicar ou melhor descrever tal diferença. Reconhece-se que abordar aspectos relacionados apenas à demanda principal, que muitas vezes é a violência sexual, pode ser insuficiente, mas não são mencionados, nem nesta fala e nem ao longo da entrevista, os aspectos específicos que devam ser enfocados quando há a ocorrência de polivitimizações. A diferença na atuação, portanto, parece estar muito mais relacionada a um aspecto subjetivo de cada profissional, do que à existência de uma decisão de maior âmbito (por exemplo: embasamento teórico) e que seja utilizada por todas e todos profissionais de um determinado serviço.

A próxima fala, de um orientador pedagógico de uma escola de educação fundamental, exemplifica a fala de tantos outros profissionais, que reconhecem os casos de polivitimização como mais críticos ou graves e que relata o que essa identificação acarreta em uma atuação que busca, de forma mais contínua e insistente, a articulação com outros serviços e instituições. Assume-se então a necessidade de que diante de casos de polivitimização é necessária uma atuação interinstitucional e intersetorial (Musicaro et al., 2017) mais robusta e significativa:

"Muda no sentido de que a gente vai...todos os casos a gente faz relatório, encaminha e tudo. Alguns casos especificos que são mais críticos, digamos... aí a gente tenta... articular mais ainda. Não que a gente não articule nos outros, mas é um caso que eu vou ficar ligando pro celular do conselheiro, eu vou ficar mandando mensagem, vou ficar reiterando ali o relatório, para poder garantir que aquilo ali seja, que aquele caso seja atendido, seja dada uma atenção para aquele caso." (Edu1)

\subsubsection{Subtema 1.3: A vitimização sexual às vezes faz sombra às outras violências}

Outro aspecto que ajuda a compor o cenário de invisibilidade da polivitimização parece se relacionar com o espaço que ocupa a violência sexual, muitas vezes reconhecida como uma violência mais grave e que vem, de fato, 
ganhando mais destaque - tanto nas divulgações midiáticas (Melo, 2020), quanto nos estudos científicos (Musicaro et al., 2017; Schwabe et al., 2018) - como é possível observar no discurso de uma profissional que compõe a equipe psicossocial de um Ministério Público:

"Em relação à violência sexual, ela é tão assim.. eu diria que é a violência pior, no sentido assim do estrago. Não sei se posso te falar isso, mas é porque.. é como se a gente, em relação à violência sexual, a gente foca nela, geralmente a gente não fala nas outras. É até interessante isso..." (MPub1)

Ainda que as consequências e possíveis sequelas de violências sexuais sejam graves (Lynas \& Hawkins, 2017) e motivo de sofrimentos intensos, especialmente quando se trata de vítimas do sexo masculino, os outros tipos de violência também geram impactos importantes para as polivítimas e seu ciclo social (Norman et al., 2012). Se há um acúmulo de violências, como no caso das polivitimizações, os impactos tendem a se somar e se amplificar, podendo gerar um senso de ineficácia que prejudica o processo de superação e a interrupção ou fim desses impactos (Guerra et al., 2016; Soler et al., 2013).

Além disso, é possível que outros tipos de violência, inclusive pelos motivos de naturalização mencionados anteriormente, nem mesmo sejam expostos a priori pelas vítimas e familiares, como comentou o profissional do serviço de saúde especializado em violência no trecho a seguir:

“Às vezes... o abuso.. a violência sexual não é nem o... Quando você vai fazer o estudo mesmo.. da família.. quando você entra no acompanhamento e atendimento... não é a principal questão... não é... porque...o abuso e a violência foi uma consequência de todo um processo que já acontecia antes, que envolvia outros tipos de violência, que não propriamente aquele (que chegou como demanda inicial)" (Sau2)

A ocorrência de um acompanhamento de cunho terapêutico que seja mais amplo, em termos de profundidade dos conteúdos trabalhados, e mais longo, em termos temporais, pode favorecer o aparecimento ou o reconhecimento de outras violências, tanto por parte das e dos profissionais, quanto por parte das próprias polivítimas e seus familiares. Dessa forma, pode ser também possível perceber os impactos de cada uma das diferentes violências existentes e abordar suas também diferentes consequências de forma específica e direcionada (Kingston et al., 2017). Para isso, no entanto, é preciso que as violências sexuais não façam sombra às outras violências e sejam também consideradas, e não apenas consideradas.

Na fala a seguir, de uma magistrada de um Juizado de Violência Doméstica e Familiar do Disitro Federal, é também possível perceber que a ocorrência de mais de uma violência é fenômeno comum quando as ocorrências policiais viram processos no âmbito judiciário, ou seja, de responsabilização.

"Com certeza (é mais frequente ter várias violências). Até as ocorrências, nunca vem só uma ameaça. Ameaçou, xingou, ofendeu, humilha.. a violência sexual vem recheada de anos e anos de humilhação, de ameaça junto.. é sempre o combo. É raro você ter um fato isolado.. e é por isso que, por exemplo, na violência sexual, na hora da gente fazer a sentença, todo o contexto... os relatórios psicossociais são importantíssimos porque o promotor pinça aí, a lei determina assim, o fato no dia tal, tal, tal, aconteceu aquilo. Mas quando você pega o relatório psicossocial de cinco a dez páginas, e você faz as entrevistas e você aciona o Conselho, e vê toda a prova.. aí você vê todos os ângulos..." (Jusl) 
Não é apenas nas instituições de cuidado, atenção e intervenção com as (poli)vítimas que a violência sexual chega como demanda principal, porém é acompanhada de outras violências. Também as e os profissionais com atribuições que visam à responsabilização das e dos possíveis ofensores percebem o "combo" da qual a violência sexual faz parte. Além disso, nesta fala também ressalta-se a importância de uma atuação conjunta da rede de atenção às (poli)vítimas. Cada profissional e instituição tem seu valor e suas distintas atribuições podem contribuir positivamente para as atribuições dos pares e outros colegas o que, por sua vez, também tende a gerar melhorias e benefícios às (poli)vítimas e seus familiares.

Para tal processo, porém, é fundamental que sejam oferecidas capacitações continuadas aos profissionais e que estas resultem em processos de atuação de cunho terapêutico que coloquem a polivitimização como foco por parte das e dos profissionais e não dependam única e exclusivamente da sensibilidade individual do profissional para perceber e identificar a ocorrência de outros tipos de violências.

\subsection{Tema 2: "A atuação profissional com a (poli)vitimização de meninos"}

Diante de um cenário em que as polivítimas muitas vezes passam despercebidas ou, ainda que sejam identificadas, não recebem um protocolo de atendimento ou intervenção psicossocial que abarque as especificidades dessa condição, a atuação profissional é um dos aspectos de extrema relevância que compõem esse contexto, podendo favorecêlo ou não.

\subsubsection{Subtema 2.1: As vantagens da experiência}

Levando em consideração este cenário complexo que aponta muitos fatores como importantes para uma condução adequada de atenção às polivítimas, a fala a seguir, de um psicólogo da Vara da Infância e da Juventude do Distrito Federal, parece apontar para uma convergência entre capacitação e conhecimento técnico e experiência e sensibilidade profissional:

"As meninas acabam tendo um atendimento um pouco melhor porque as Varas, os juizes de Violência Doméstica são mais experientes na coisa da violência doméstica, entendem a dinâmica, entendem a retratação e tudo. Então um terço das crianças do Distrito Federal vítimas que vão pro judiciário, que é mais ou menos o número de casos notificados (de meninos) que entram, né, para a rede, um terço, então um terço dessa população fica meio no limbo, que são esses meninos." (Jus2)

Neste trecho a desproteção a que os meninos ficam suscetíveis no contexto judiciário fica evidente, pois, enquanto para as meninas os processos ficam sob responsabilidade de profissionais que trabalham em Juizados especializadas em violência doméstica, os processos deles, no Distrito Federal, ficam em Varas Criminais ou Juizados comuns. Importa ressaltar que há a previsão legal para a criação de Varas especializadas em crimes sexuais contra crianças e adolescentes (Brasil, 2017), que abarcaria este público do sexo masculino. Enquanto tal previsão não é efetivada em todo o país, salienta-se como as crianças e adolescentes do sexo feminino que sofrem violências têm seus processos analisados e julgados por magistradas e magistrados com maior especialização no assunto, uma vez que discussões relacionadas à conteúdos de gênero, por exemplo, precisam ser constantemente conduzidas para se atuar em Juizados de violência doméstica.

Por outro lado, as e os magistrados de varas criminais acumulam uma série de crimes, que não o sexual, no rol de suas atribuições. Tal fato não apenas coloca como um desafio a questão de se aprofundar e especializar em um 
determinado crime - como a violência sexual contra meninos -, mas também pode se apresentar como desafio, pois a ocorrência de casos de violência sexual contra meninos na rotina profissional dessas e desses magistrados é menor, o que limita a atuação e experiência delas e deles com essa temática (Chan et al., 2019).

Por isso, menos capacitação e menos experiência podem prejudicar a compreensão do fenômeno por parte das e dos profissionais, mormente porque há diversas características das violências contra crianças e adolescentes, especialmente as intrafamiliares, que divergem de outros crimes comuns, também analisados e julgados nas Varas onde ficam os processos de violências contra crianças e adolescentes do sexo masculino: a ausência de provas físicas e materiais, a proximidade e proteção que por vezes às vítimas fazem de seus/suas ofensores/as, o fenômeno da retração (Palermo et al., 2019; Ressel et al., 2018), etc.

\subsubsection{Subtema 2.2: Ambiguidades e confusões na atuação profissional}

Neste cenário de atuação profissional em que há pouco incentivo institucional e político para que haja espaço e atenção diferenciadas às polivítimas do sexo masculino, é compreensível que existam lacunas, ambiguidades, contradições, confusões e até falhas na atuação das e dos profissionais que trabalham com esses meninos. Neste trecho de fala de uma psicóloga de um Centro Integrado, pertencente no Distrito Federal à Secretaria de Justiça, é possível observar a ocorrência de uma importante reflexão acerca desses atendimentos às (poli)vítimas do sexo masculino:

“Eu to mobilizada com essa história dos meninos estarem esquecidos na minha cabeça, apesar da gente atender vários meninos.. várias crianças e meninos, assim.. é.. eles estão meio esquecidos, fiquei preocupada com isso. Vou dar uma olhada no.. porque.. claro, eu sei o porquê um pouco, de que a violência sexual acaba que se expande para a menina numa faixa etária muito forte, né, mas que eles também precisam de estratégia, de cuidado. Vou ver com as meninas do Centro se a gente também tá negligenciando um olhar para esses meninos. vou conversar com elas." (Jus3)

Nesta fala, também fica destacado como a participação em uma entrevista focando em determinada temática pode contribuir para um processo de reflexão e autoavaliação. A partir dessa reflexão e autoavaliação, pode ser possível alcançar alguma mudança na prática e no exercício profissional, um dos objetivos de uma pesquisa-ação (Barbier, 2004), como foi a proposta de pesquisa, ainda em andamento e de onde os resultados aqui apresentados foram extraídos. Neste trecho também fica clara certa confusão acerca da diferenciação entre meninos e meninas, também presente na fala de profissionais de outras áreas de atuação, ainda que a profissional demonstre preocupação e iniciativa em avaliar a estratégia que está sendo adotada para às crianças e adolescentes do sexo masculino.

No entanto, ainda que exista motivação individual para as e os profissionais se capacitarem e apresentarem um trabalho mais acolhedor e atento, não é possível se dissociar do contexto macrossocial, político e econômico a que estamos inseridos no Brasil. Tal contexto é marcado por estereótipos e preconceitos dirigidos a diversos assuntos, além de ter como uma de suas características a própria questão da violência, quase como algo natural. Porém, é possível encontrar documento oficial que orienta a prática de atenção à violência contra criança e adolescente sob iniciativa do Ministério da Saúde (2010).

Certas categorias profissionais se deparam com esse desafio de forma mais acentuada, como é o caso da segurança pública que carrega em sua imagem de senso comum a violência como algo característico de seus e suas profissionais e, portanto, de sua atuação (Leclerc \& Wortley, 2015). No trecho a seguir, de um policial militar que atua em um programa da Polícia Militar do Distrito Federal orientado ao enfrentamento da violência doméstica, é possível 
observar a complexidade das atuações dele e de seus colegas:

"A violência é um.. é um.. no fim, você tem que ser.. você tem que ser.. a questão não é violento, você tem que ser mais.. enérgico, para a pessoa entender que aquilo vai funcionar. O estado não vai recuar (...). Então a violência aqui, para mim, a violência é um fator decisivo, eu não queria ser violento com ninguém, eu sou um policial que eu quero sempre... quanto mais fácil para mim melhor, não vou para um lugar que eu quero ser violento, não quero ser violento com ninguém.. mas, de repente, as pessoas às vezes vê o.. aqui, na Ceilândia, particularmente, eles interpretam a educação como fraqueza, não sei porquê.. não gostaria que fosse assim. Em outros lugares também, não gostaria que fosse assim. A gente vai aumentando o.. o uso progressivo da força, porque a gente chega primeiro educado, tem a nossa presença, tem a nossa verbalização.. a nossa verbalização às vezes com calma, com parcimônia.. Quando as pessoas filmam, que vai para a imprensa, eles não mostram a.. quando.. o antes daquilo ali, só mostra depois que o policial já tava sendo agressivo, mas teve uma história antes, sempre tem uma história antes. Às vezes acontece de o policial já tá estressado com outra coisa e tal e chega sendo agressivo, mas isso não é.. isso não é a regra, isso é a exceção. Acho que a violência ela aqui é.. eu não gostaria de ser violento em nenhuma ocasião. Já precisei ser, gostaria de não ter sido em nenhuma, até porque.. a gente estuda, a gente passa num concurso público, a gente sabe que.. você às vezes sendo violento você pode ser expulso da polícia, você pode sair daquilo lá e te acarretar problemas, então ninguém é burro de ficar procurando problema." (SPub2)

A ambiguidade e contradição presentes neste trecho incide exatamente na forma como a prática violenta é, ao mesmo tempo, criticada e praticada por um profissional que tem como objetivo interromper e cessar outras formas de violência. Ressalta-se, contudo, que este cenário não faz parte apenas da atuação deste profissional em específico, mas sim de toda uma construção histórica que coloca nesta categoria profissional de segurança pública, especialmente como neste caso, dos policiais militares, o caráter enérgico de suas atuações. Tal prática, por sua vez, também é comumente esperada e privilegiada na expressão comportamental de crianças e adolescentes do sexo masculino, aproximando-os.

\section{Considerações Finais}

Considera-se a polivitimização um tema de grande relevância social e acadêmica, especialmente focalizando as polivítimas do sexo masculino, como é a proposta deste texto. A possibilidade de aprofundar e discutir aspectos que compõem o resultado de uma pesquisa mais ampla e ainda em andamento é também um dos pontos fortes desta pesquisa, uma vez que a atuação das e dos profissionais é um dos elos fundamentais para que esse fenômeno seja mitigado. Além disso, é um estudo que conta com a participação de profissionais de sete diferentes áreas de atuação e de diferentes instituições e essa diversidade possibilita um olhar amplo e complexo sobre o tema, especialmente por se tratar de uma pesquisa qualitativa, em que é possível apresentar o processo reflexivo das e dos profissionais entrevistados, por meio das falas e opiniões.

Com os resultados e a discussão aqui apresentada já se coloca a urgência de reconhecer e nomear a polivitimização para que esta definição seja o primeiro passo no estabelecimento de um atendimento institucional mais específico e aprofundado. Ademais, este trabalho também apresenta reflexões críticas no sentido de desnaturalizar vivências familiares e comunitárias que são marcadas e caracterizadas por violência, mas que de tão frequentes não são assim percebidas. Não definir e não delinear violência psicológica, violência urbana e violência estrutural, por exemplo, 
faz com que os esforços para minimizar ou interromper esses problemas não sejam feitos, pois é como se nem se cogitasse a possibilidade de se fazer diferente.

A naturalização de práticas violentas dentro das famílias, dentro das comunidades em que vivem essas famílias, e dentro das instituições por onde passam essas famílias é um problema de relevância ímpar e que precisa ser constantemente relembrado e estudado. Além disso, o contexto que perpassa os profissionais que atendem e acolhem essas polivítimas e seus familiares também precisa de investimento para que não sejam as instituições públicas locais de perpetuação de violências.

Por isso, ressalta-se aqui também o impasse em relação ao aspecto subjetivo da intervenção diferenciada para os casos de polivitimização: a sensibilidade e subjetividade profissional precisam sim ser consideradas como aliadas para o oferecimento de um atendimento ou intervenção de qualidade, mas depender apenas de tal sensibilidade para a condução dos circuitos protetivos da vítima parece ser arriscado. No circuito de responsabilização, protagonizado principalmente por instituições das áreas Ministério Público, Justiça e Segurança Pública, foi possível observar de forma um pouco mais clara, a partir dos resultados, como aspectos bem objetivos do fenômeno polivitimização são levados em consideração e guiam as atuações das e dos profissionais - diferentes crimes praticados por um(a) mesmo(a) ofensor(a) aumentando a pena, por exemplo.

Esse impasse que valoriza e, ao mesmo tempo, coloca como insuficiente a subjetividade ou competência individual de cada profissional reflete a complexidade do fenômeno que se mostra mais uma vez presente: em alguns momentos deve-se priorizar um caráter menos circunscrito e mais flexível e subjetivo das atuações profissionais, mas isso não quer dizer que posturas estruturadas, bem marcadas e com um caráter objetivo que seja previsto institucionalmente não tenham função ou valor nos atendimentos e intervenções para a polivitimização. $\mathrm{O}$ caráter complexo na atuação diante deste fenômeno, portanto, apresenta como desafio a necessidade de compor uma estratégia de enfrentamento à polivitimização que à princípio pode parecer paradoxal e até mesmo excludente, mas que sob o viés dos paradigmas da complexidade, instabilidade e intersubjetividade (Esteves de Vasconcellos, 2005) fazem sentido e são fundamentais. Não por isso deve ser ignorado o desafio imposto: aproximar as instituições e suas e seus profissionais destes conceitos e de tantos outros, treinando-os e qualificando-os para conseguir, em alguma medida, ter um repertório de atuação vasto, que reconheça as especificidades de cada caso, processo, contexto e momento. Só assim será possível alcançar e atuar sobre a polivitimização com a seriedade, abrangência e profundidade requeridas.

Ainda que os resultados tenham sido coletados em apenas um ente da federação, não se considera esse recorte uma limitação, mas sim um primeiro passo no sentido de privilegiar esse tema e aprofundar o conhecimento sobre a polivitimização. Como principal limitação deste texto coloca-se a impossibilidade de tecer comparações e aproximações com outros estudos nacionais que sejam semelhantes e com o mesmo escopo, em função da ausência dos mesmos. Por isso, sugere-se, em pesquisas futuras, que sejam feitas pesquisas que busquem também acessar profissionais de outros estados da federação, para que o avanço na compreensão da polivitimização seja ainda maior e possa, com o tempo e o maior número de pesquisas, ajudar a compor o cenário do fenômeno polivitimização a nível nacional.

\section{Referências}

Araújo, E. M., \& Ataíde, M. A. (2018). Serviço Social: intervenção em um hospital de urgência e emergência diante da rede de atenção ao paciente jovem vítima de violência urbana. Tempus. Acta de Saúde Coletiva, 11(2), 69-87. http://dx.doi.org/10.18569/tempus.v11i2.2233

Brasil (1990). Lei no 8.069 de 13 de julho de 1990: Dispõe sobre o Estatuto da Criança e do Adolescente. http://www.planalto.gov.br/ccivil_03/leis/18069.htm

Barbier, R. (2004). A pesquisa-ação. Liber Livro. 
Brasil (2005). Política Nacional de Assistência Social - PNAS/2004. Norma Operacional Básica - NOB/SUAS. https://www.mds.gov.br/webarquivos/publicacao/assistencia_social/Normativas/PNAS2004.pdf

Brasil (2017). Lei $\mathrm{n}^{\circ} 13.431$ de 4 de abril de 2017: Estabelece o sistema de garantia de direitos da criança e do adolescente vítima ou testemunha de violência e altera a Lei no 8.069 de 13 de julho de 1990. http://www.planalto.gov.br/ccivil_03/_ato2015-2018/2017/lei/113431.htm

Braun, V., \& Clarke, V. (2006). Using thematic analysis in psychology. Qualitative Research in Psychology, 3(2), 77-101. https://doi.org/10.1191/1478088706qp063oa

Braun, V., \& Clarke, V. (2019). Reflecting on reflexive thematic analysis. Qualitative Research in Sports, Exercise and Health, 11(4), 589-597. https://doi.org/10.1080/2159676X.2019.1628806

Braun, V., Clarke, V., Hayfield, N., \& Terry, G. (2019). Thematic analysis. In P. Liamputtong (Ed.), Handbook of research methods in health social sciences. Springer. https://doi.org/10.1007/978-981-10-5251-4

Brito, E. F. \& Bonini, L. (2019, 12 de dezembro). Políticas Públicas para o Acesso à Justiça. Âmbito Jurídico. https://ambitojuridico.com.br/cadernos/direitoconstitucional/politicas-publicas-para-o-acesso-a-justica/

Burns, C. R., Ladgon, S., Boyda, D., \& Armour, C. (2016). Interpersonal polyvictimization and mental health in males. Journal of Anxiety Disorders, 40, 7582. http://doi.org/10.1016/j.anxdis.2016.04.022

Centro de Referência em Educação Integral (2014). Sistema de Garantia de Direitos. https://educacaointegral.org.br/glossario/sistema-de-garantia-de-direitos/

Chan, K. L., Chen, Q., Chen, M., Lo, C. K. M., \& Yu, L. (2019). Screening for Multiple Types of Family Violence: Development and Validation of the Family Polyvictimization Screen. Frontiers of Public Health, 7, 282. https://doi.org/10.3389/fpubh.2019.00282

Esteves de Vasconcellos, M. J. (2002). Pensamento sistêmico: o novo paradigma da ciência. Papirus.

Finkelhor, D., Ormrod, R. K., Turner, H. A., \& Hamby, S. L. (2005). Measuring poly-victimization using the Juvenile Victimization Questionnaire. Child Abuse \& Neglect, 29, 1297-1312. http://doi.org/10.1016/j.chiabu.2005.06.005

Finkelhor, D., Ormrod, R. K., \& Turner, H. A. (2007). Poly-victimization: A neglect component in child victimization. Child Abuse \& Neglect, 31, 7-26. http://doi.org/10.1016/j.chiabu.2006.06.008

Finkelhor, D., Hamby, S., Turner, H., \& Ormrod, R. (2011). The Juvenile Victimization Questionnaire: 2nd Revision (JVQ-R2). Crimes Against Children Research Center.

Gauthier-Duchesne, A., Hébert, M., \& Daspe, M.E. (2017). Gender as a predictor of posttraumatic stress symptoms and externalizing behavior problems in sexually abused children. Child Abuse \& Neglect, 64, 79-88. http://doi.org/10.1016/j.chiabu.2016.12.008

González-Rey, F. (2010). Pesquisa qualitativa e subjetividade: os processos de construção da informação. Cengage Learning.

Guerra, C., Ocaranza, C., \& Weinberger, K. (2016). Searching for social support moderates the relantionship between polyvictimization and externalizing symptoms: a brief report. Journal of Interpersonal Violence, 34(3), 1-10. https://doi.org/10.1177/0886260516642293

Guerra, C., Pereda, N., Guilera, G., \& Abad, J. (2016). Internalizing symptoms and polyvictimization in a clinical sample of adolescent: the roles of social support and non-productive coping strategies. Child Abuse \& Neglect, 54, 57-65. doi:10.1016/j.chiabu.2016.03.0040145-2134

Hlavka, H. R. (2016). Speaking of Stigma and the Silence of Shame: Young Men and Sexual Victimization. Men and Masculinities, 20(4),1-24. https://doi.org/10.1177/1097184X16652656

Hohendorff, J. V., Habigzang, L. F., \& Koller, S. H. (2017). “A boy, being a victim, nobody really buys that, you know?”:Dynamics of sexual violence against boys. Child Abuse and Neglect, 70, 53-64. http://doi.org/10.1016/j.chiabu.2017.05.008

Kingston, D. A., Graham, F. J., \& Knight, R. A. (2017). Relations Between Self-Reported Adverses Events in Childhood and Hipersuality in Adult Male Sexual Offenders. Archives of Sexual Behavior, 46, 707-720. https://doi.org/10.1007/s10508-016-0873-5

Leclerc, B. \& Wortley, R. (2015). Predictors of victim disclosure in child sexual abuse: additional evidence from a sample incarcerated addulkts sexual offenders. Child Abuse \& Neglect, 43, 104-111. http://dx.doi.org/10.1016/j.chiabu.2015.03.003

Lynas, J., \& Hawkins, R. (2017). Fidelity in school-based child sexual abuse prevent programs: A systematic review. Child Abuse and Neglect, 72, 10-21. http://doi.org/:10.1016/j.chiabu.2017.07.003

Ministério da Saúde (2010). Linha de Cuidado para a Atenção Integral à Saúde de Crianças, Adolescentes e suas Famílias em Situação de Violência. https://portaldeboaspraticas.iff.fiocruz.br/biblioteca/linha-de-cuidado-para-a-atencao-integral-a-saude-de-criancas-adolescentes-e-suas-familias-em-situacaode-violencias/

Melo, K. (2020, 18 de maio). Denúncias de violações contra crianças e adolescentes aumentam 14\%. Agência Brasil. https://agenciabrasil.ebc.com.br/direitoshumanos/noticia/2020-05/denuncias-de-violacoes-contra-criancas-e-adolescentes-aumentam-14

Musicaro, R. M., Spinazzola, J., Arvidson, J., Swaroop, S. R., Grace, L. G., Yarrow, A., Suvak, M. K., \& Ford, J. D. (2017). The Complexity of Adaptation to Childhood Polyvictimization in Youth and Young Adults: Recommendations for Multidisciplinary Responders. Trauma, Violence, \& Abuse, 20(1), 81-98. https://doi.org/10.1177/1524838017692365

Norman, R. E., Byambaa, M., De, Rumma, Butchart, A., Scott, J., \& Vos, T. (2012). The long-term health consequences of child physical abuse, emotional abuse, and neglect: a systematic review and meta-analysis. PLOS Medicine, 9(11), 1-31. 
Research, Society and Development, v. 10, n. 2, e40710212920, 2021

(CC BY 4.0) | ISSN 2525-3409 | DOI: http://dx.doi.org/10.33448/rsd-v10i2.12920

Oliveira, J. R., Costa, M. C. O., Amaral, M. T. R., Santos, C. A., Assis, S. G. \& Nascimento, O. C. (2014). Violência sexual e coocorrências em crianças e adolescentes: estudo das incidências ao longo de uma década. Ciência \& Saúde Coletiva, 19(3), 759-771. http://dx.doi.org/10.1590/141381232014193.18332013.

OPAS Brasil (2020, 11 de março). OMS afirma que COVID-19 é agora caracterizada como pandemia. https://www.paho.org/bra/index.php?option=com_content\&view=article\&id=6120:oms-afirma-que-covid-19-e-agora-caracterizada-comopandemia\&Itemid $=812$

Palermo et al. (2019). Risk factors for childhood violence and polyvictimization: A cross-country analysis from three regions. Child Abuse \& Neglect, 88, 348-361. https://doi.org/10.1016/j.chiabu.2018.10.012

Penso, M. A., Conceição, M. I. G., Costa, L. F., Said, A. P., \& Williams, L. C. (2019). Boy sexual victimization: Characteristics of family configuration and of the offender. Psicologia Teoria e Pesquisa, 35. https://doi.org/10.1590/0102.3772e35428

Pereira, A. S., Shitsuka, D. M., Parreira, F. J., \& Shitsuka, R. (2018). Metodologia da pesquisa científica [ebook]. Universidade Federal de Santa Maria e Núcleo de Tecnologia Educacional.

Ressel, M., Lyons, J., \& Romano, E. (2018). Abuse Characteristics, Multiple Victimization and Resilience Among Young Adult Males with Histories of Childhood Sexual Abuse. Child Abuse Review, 27(3), 239-253. https://doi.org/10.1002/car.2508

Schwabe-Reese, L. M., Currie, D., Mishra, A. A., \& Peek-Asa, C. (2018). A Comparison of Violence Victimization and Polyvictimization Experiences Among Sexual Minority and Heterosexual Adolescents and Young Adults. Journal of Interpersonal Violence, 1-18. https://doi.org/10.1177/0886260518808853

Soares, A. M. (2015). Violência como fenômeno intrínseco à cultura política brasileira. Sinais, 2(18), 92-108.https://doi.org/10.25067/s.v2i18.13254

Soler, L., Kirchner, T., Paretilla, C. \& Forns, M. (2013). Impact of poly-victimization on mental health: the mediator and/or moderator role of self-esteem. Journal of Interpersonal Violence, 28(13), 2695-2712.https://doi.org/10.1177/0886260513487989

Turner, H. A., Shattuck, A., Finkelhor, D., \& Hamby, S. (2016). Polyvictimization and youth violence exposure across contexts. Journal of Adolescent Health, 58(2), 208-214. http://doi.org/10.1016/j.jadohealth.2015.09.021 